\title{
Nurses' Awareness Regarding Zika Virus in Beni-Suef Governorate
}

\author{
Ahmed Abd-Elhakim Elgendy ${ }^{1}$, Hanan Elzeblawy Hassan ${ }^{2 *}$, Fathya Elsaid Elsaid ${ }^{3}$ \\ Eman EL_Sherbeny ${ }^{4}$ \\ ${ }^{1}$ Assistant Prof. of Medical Physiology, Faculty of Medicine, Mansoura University, Egypt \\ ${ }^{2 *}$ Maternal and Newborn Health Nursing, Faculty of Nursing, Beni-Suef University, Egypt \\ ${ }^{3}$ Lecturer of Pediatric nursing, Faculty of nursing, Fayoum University, Egypt \\ ${ }^{4}$ Lecturer of Community Health nursing, Faculty of Nursing, Beni-Suef University, Egypt \\ nona_nano_1712@yahoo.com
}

\section{Abstract}

Background: Some studies had linked Zika virus infection to congenital neurological malformation as microcephaly.

Aim: Aim of the study is to assess the awareness and knowledge orientation of outpatient nurses about effects of Zika virus on the pregnancy and birth outcome in governmental Hospitals in Beni-Suef Governorate.

Subjects \& Methods: Quasi-experimental design was used to conduct this study. A purposive sampling of 131 nurses was working at antenatal, obstetric and gynecological inpatient ward, outpatient and MCH clinics BeniSuef City, during the period of the study.

Results: clarifies that more than half of women (59.5\%) were not oriented by Zika virus, $65.0 \%$ reported that insect bite is the main mode of disease transmission. unfortunately, $69.5 \%$ of nurses didn't know that Zika virus affecting the baby. In addition, $65.7 \%$ didn't know that it can affect the pregnancy outcome, $32.9 \%$ of nurses reported that environmental sanitation is the main method of prophylactic measure,35.2\% of nurses reported that bed rest is the best method of symptomatic treatment, $64 \%$ of nurses had good knowledge about Zika virus, there is a significant relation $(<0.001)$ only were found between nurses age, education, and pregnancy status and their knowledge regarding Zika virus and nurses' knowledge regarding Zika virus were improved. A significant relation was found $(<0.001)$.

Conclusion: Almost nurses were not oriented to Zika virus and had poor knowledge score. They didn't know the main mode of disease transmission, didn't know that Zika virus may affect their pregnancy outcome. Younger age, better education, and pregnant nurses were more knowledgeable comparing with older, lower educational level and non-pregnant ones.

Recommendations: implement health education program to increase awareness of the nurses working in outpatient clinic about Zika Virus and its effects on pregnant women and birth outcome.

Keywords: Zika virus, Awareness, Beni-Suef

\section{INTRODUCTION}

Zika virus is an arthropod-borne virus in the genus of Flavi virus since identification of Zika virus infection in Brazil in May 2015; the virus has spread throughout the Americas [1]. Up to February2016; 28 countries of the region had reported cases. Although infection with Zika virus often leads to mild disease, its emergence in the Americas has coincided with a steep increase in patients developing Guillain-Barré syndrome (an autoimmune disorder that causes acute or sub-acute flaccid paralysis) and the birth of babies with neurological complications, 
such as congenital microcephaly. Congenital microcephaly is a neurological abnormality that is present at birth and defined as head circumference at least 2 SD smaller than the mean for sex, age, and ethnicity, with head circumference at least 3 SD smaller being deemed severe. Microcephaly might occur alone or in combination with other abnormalities. The condition is associated with a reduction in brain volume and frequently with intellectual disabilities, motor disabilities, or both, including speech impairment, poor neurocognitive outcome, and behavioral issues. Causes include genetic or environmental factors during pregnancy that affect fetal brain development. Prenatal viral infections (e.g., rubella or cytomegalovirus), maternal alcohol use, and hypertensive disorders have been associated. Cases have also been reported after intrauterine infection with West Nile virus (another Flavi virus) and Chikungunya virus [2].

The incubation period of Zika virus disease is not clear but is likely to be a few days [3]. The symptoms are similar to other Arbovirus infections such as dengue and include fever, skin rashes, conjunctivitis, muscle \& joint pain, malaise, and headache. These symptoms are usually mild and last for 2-7 days [4]. After a comprehensive review of the evidence; there is a scientific consensus that Zika virus is a cause of microcephaly and GuillainBarré syndrome. Intense efforts are continuing to investigate the link between Zika virus and a range of neurological disorders, within a rigorous research framework. Zika virus is primarily transmitted to people through the bite of an infected mosquito from the Aedes genus, mainly Aedesaegypti in tropical regions [5]. Aedes mosquitoes usually bite during the day, peaking during early morning and late afternoon/evening. This is the same mosquito that transmits dengue, Chikungunya and yellow fever [6]. Sexual transmission of Zika virus is also possible [7]. Other modes of transmission such as blood transfusion are being investigated [8].

On the basis of the available evidence, the public health response to the outbreak of Zika virus disease has moved forward, with the distribution of health messages about the importance of mosquito-bite prevention, recommendations by public health authorities in some of the most severely affected countries to delay pregnancy, and advisories that pregnant women avoid travel to areas with active Zika virus transmission [9]. However, communications regarding Zika virus have been challenging: a recent survey showed low levels of knowledge and concern about Zika virus in the United States [10]. The recognition of Zika virus as a cause of microcephaly and other serious brain anomalies would allow for more direct communication, which might lead to improved understanding of / and adherence to public health recommendations [9]. Therefore, a review of the evidence linking Zika virus infection and adverse pregnancy and birth outcomes is needed.

Infection with Zika virus may be suspected based on symptoms and recent history of travel (e.g. residence in or travel to an area with active Zika virus transmission). A diagnosis of Zika virus infection can only be confirmed through laboratory tests on blood or other body fluids, such as urine, saliva or semen. Zika virus disease is usually mild and requires no specific treatment. People sick with Zika virus should get plenty of rest, drink enough fluids, and treat pain and fever with common medicines [11]. If symptoms worsen, they should seek medical care and advice. There is currently no vaccine available.

Egypt has already taken preventative measures against Zika outbreak: Health Ministry. According to Megahed 2016, the spokesperson for the Ministry of Health, he emphasized that, the ministry is working on securing two aspects; firstly, secure all ports and airports by screening and moving any individuals who may have come in contact with the virus into quarantine, secondly, test mosquitoes and carefully monitor the spread of the virus. These preventative measures already existed in Egypt before the state of emergency was declared [12].

The World Health Organization (WHO) declared virus Zika a public health emergency of international concern in an official statement, after a teleconference meeting with 18 health experts. At present, the most important protective measures are the control of mosquito populations and the prevention of mosquito bites for at-risk individuals, especially pregnant women, the statement read. The experts agreed in the statement that a causal relationship between Zika infection during pregnancy and microcephaly is strongly suspected, though not yet scientifically proven. However, WHO calls for the urgent need to coordinate international efforts to investigate and better understand this relationship [9]. 


\section{THE SignificANCE OF THE STUdY}

Zika virus was spread in 28 countries; it combed too many complications especially in the newborn. This conducting can prevent spread and increase awareness of the community as a whole as well as the physician, nurses and health care provider worked in outpatient clinic about Zika virus to prevent it. The nursing care is the main critical component of care for women who experience pregnancy. So, nurses' Knowledge deficit and poor practical skills and care surely will interfere with their ability to achieve consistent and positive patient care outcomes [13]. Maternity and Community nurses play an important role with the physician in prophylaxis. Protection against mosquito bites is a key measure to prevent Zika virus infection. This can be done by wearing clothes (preferably light-colored) that cover as much of the body as possible; using physical barriers such as window screens or closing doors and windows; sleeping under mosquito nets, and; using insect repellent containing DEET, IR 3535 or Icaridin according to the product label instructions [14]. Special attention and help should be given to those who may not be able to protect themselves adequately, such as young children, the sick or elderly. Travelers and those living in affected areas should take the basic precautions described above to protect themselves from mosquito bites. It is important to cover, empty or clean potential mosquito breeding sites in and around houses such as buckets, drums, pots, gutters, and used tires. Communities should support local government efforts to reduce mosquitoes in their locality. Health authorities may also advise that spraying of insecticides be carried out. So the aim of the project will increase awareness of nurse worked in the outpatient clinics because they contact with many client during their work. So nurses have a unique position as education.

\section{AIM OF THE STUDY}

The aim of the study is to assess the awareness and knowledge of nurses working antenatal, obstetric and gynecological inpatient ward and outpatient clinics at all government hospitals as well as, all Primary Healthcare Centers in Beni-Suef City about Zika virus and its effect on the pregnancy and birth outcome.

\section{RESEARCH QUESTIONS}

To what degree nurses aware and orient by Zika virus and its effect on pregnancy?

\section{Design, Subjects and Methods}

A descriptive design was used to conduct this study, a purposive sampling of 131 nurses working at antenatal, obstetric and gynecological inpatient ward and outpatient clinics at all government hospitals as well as, all Primary Healthcare Centers in Beni-Suef City.

\section{TOOL For DATA COLLECTION}

A structured self-administered questionnaire was developed by the researchers, in Arabic language, after reviewing the related literature. It consists of two sections: section I: Includes socio-demographic characteristics, obstetrical history of nurses as age, level of education and income. Section II: This part consisted of items related to nurses ' knowledge about Zika virus (definition, risk factors, mode of transmission, signs and symptoms, treatment, and method of prevention)

Scoring of the items: Each correct answer was given a score equal "2", the wrong answer was given a score equal " 1 " and don't know the answer was given a score equal "zero". Scoring key for the knowledge was as the following

1. Good knowledge $\geq 75 \%:<100 \%$. (20-26)

2. Fair knowledge $\geq 50 \%:<75 \%$. (13-19)

3. Poor knowledge $\geq 0:<50 \%$. $(0-12)$ 


\section{Methods of Data Collection}

This study was covered in four phases

The validity of tool: 5 experts reviewed the content validity of the tool from maternity, obstetric and gynecological (nursing \& medical physicians) and community health nursing specialists in the field.

Ethical considerations: Approval was taken from hospitals and $\mathrm{MCH}$ directors before starting the research and data were collected after explaining the aim of the study to all nurses who participated in the study.

Pilot study: A simple, comprehensive, well-designed questionnaire was introduced to 13 nurses as a pilot study. Feedbacks of the nurses and the professors were collected and considered in the second version of the questionnaire.

Fieldwork:

- Data were collected from all previously mentioned setting at six months from September 2015 until February 2016.

- Each nurse takes time approximately between 30-45 minutes to fill a pretest questionnaire.

- The education session about Zika virus was prepared based on the review of literature. The developed content was given to five experts to establish the content validity and they were requested to give their opinion and suggestions about the content of the session. According to expert's suggestions, the content was modified.

- The previously mentioned evaluations were performed for all nurses twice; before commencing the educational program and after finishing it.

Statistical analysis: Data were analyzed using SPSS. Frequency distribution with its percentage and descriptive statistics with mean and standard deviation were calculated. Chi-square, correlations were done whenever needed. $\mathrm{P}$ values of less than 0.05 were considered significant.

\section{RESULTS}

Table (1): shows that more than one third (39.7\%) of the nurses were in age group between 20-22 years and all of them (100.0\%) were female, more than half (52.0\%) had institute level of education, finally, the around half $(49.0 \%)$ of them were pregnant.

Table1. Nurses' characteristics ( $N=131)$

\begin{tabular}{|l|l|l|}
\hline Variables (Nurses characteristics) & Frequency & Percent \% \\
\hline Age & 34 & 26 \\
\hline $18-20$ & 52 & 39.7 \\
\hline $20-22$ & 27 & 20.6 \\
\hline $22-24$ & 18 & 13.7 \\
\hline$>24$ & 131 & 100 \\
\hline Total & 22 & 16 \\
\hline Level of education & 68 & 52 \\
\hline Diploma (Nursing School) & 41 & 32 \\
\hline Technical Institute of Nursing & \multicolumn{2}{|l|}{} \\
\hline Faculty of Nursing Graduates & 0 & 0 \\
\hline Sex & 131 & 100 \\
\hline Male nurses & \multicolumn{2}{|l|}{} \\
\hline Female nurses & 67 & 51 \\
\hline Pregnancy state & 64 & 49 \\
\hline Non pregnant & \multicolumn{2}{|l|}{} \\
\hline Pregnant &
\end{tabular}


Nurses' Awareness Regarding Zika Virusin Beni-Suef Governorate

Table (2): clarifies that more than half of nurses (59.5\%) were not oriented by Zika virus. $65.0 \%$ reported that insect bite is the main mode of disease transmission. Unfortunately, $69.5 \%$ of nurses didn't know that Zika virus affecting the baby; in addition, $65.7 \%$ didn't know that it can affect the pregnancy outcome.

Table2. Nurses' Knowledge regarding Zika virus

\begin{tabular}{|c|c|c|}
\hline Variables & Frequency & Percentage \\
\hline \multicolumn{3}{|l|}{ Zika Orientation } \\
\hline No & 78 & 59.5 \\
\hline Yes & 53 & 40.5 \\
\hline Total & 131 & 100 \\
\hline \multicolumn{3}{|c|}{ Mode of transmission } \\
\hline Insect bite & 85 & 65 \\
\hline Animal bite & 46 & 35 \\
\hline \multicolumn{3}{|l|}{ Affected babies } \\
\hline No & 91 & 69.5 \\
\hline Yes & 40 & 30.5 \\
\hline \multicolumn{3}{|l|}{ Clinically oriented } \\
\hline No & 91 & 69.5 \\
\hline Yes & 40 & 30.5 \\
\hline \multicolumn{3}{|l|}{ Clinical picture } \\
\hline Fever & 20 & 15.3 \\
\hline Rigor & 28 & 21.4 \\
\hline Conjunctivitis & 30 & 22.9 \\
\hline Muscle pain & 17 & 12.9 \\
\hline Bone ache & 20 & 15.3 \\
\hline Body aches & 16 & 12.2 \\
\hline \multicolumn{3}{|l|}{ Duration of disease } \\
\hline One day & 50 & 38.2 \\
\hline Two days & 17 & 13 \\
\hline One week & 31 & 23.7 \\
\hline More than one week & 33 & 25.2 \\
\hline \multicolumn{3}{|c|}{ Does the disease affect pregnancy outcome? } \\
\hline No & 86 & 65.7 \\
\hline Yes & 45 & 34.3 \\
\hline \multicolumn{3}{|c|}{ To what degree , Zika virus affects the pregnancy outcome? } \\
\hline Microcephaly & 93 & 71 \\
\hline Anomalies & 38 & 29 \\
\hline
\end{tabular}

Table (3): denoted that $32.9 \%$ of nurses reported that environmental sanitation is the main method of prophylactic measure, $35.2 \%$ of nurses reported that bed rest is the best method of symptomatic treatment. 
Nurses' Awareness Regarding Zika Virusin Beni-Suef Governorate

Table3. Nurses' Knowledge about Zika virus management
\begin{tabular}{|l|l|l|}
\hline Variables & Frequency & Percentage \\
\hline Prophylactic measure taken & 43 & 32.9 \\
\hline Environmental sanitation & 43 & 10.9 \\
\hline By clinical picture & 14 & 26 \\
\hline Doctor checkup & 34 & 30.6 \\
\hline Investigation & 40 & 100 \\
\hline Total & 131 & 39 \\
\hline Precautions taken & \multicolumn{3}{l|}{} \\
\hline Insect control & 51 & 11.5 \\
\hline Cleaning & 15 & 13.7 \\
\hline Waste management & 18 & 17.6 \\
\hline Insecticides & 23 & 10.9 \\
\hline Water sanitation & 14 & 7.6 \\
\hline Food sanitation & 10 & \\
\hline Symptomatic treatment & \multicolumn{2}{|l|}{} \\
\hline Taking warm drinks & 50 & 31.4 \\
\hline Taking paracitamol & 25 & 15.7 \\
\hline Bed rest & 56 & 35.2 \\
\hline Analgesics rather than paracetamol & 57.2 \\
\hline No & 91 & 25.2 \\
\hline Yes & 40 & $72.5 \%$ \\
\hline
\end{tabular}

Table (4): shows that $16.8 \%$ of nurses had good knowledge about Zika virus, while $72.5 \%$ of them had poor knowledge score, $($ mean \pm SD) $=20.14 \pm 5.94$.

Table4. Nurses' grade of knowledge about Zika virus

\begin{tabular}{|l|l|l|l|}
\hline Grade of knowledge about Zika virus & Frequency & Percentage & (mean \pm SD) \\
\hline Poor $(0-12)$ & 95 & 72.5 & \multirow{2}{*}{$20.14 \pm 5.94$} \\
\hline Fair $(13-19)$ & 14 & 10.7 & \\
\cline { 1 - 3 } Good $(20-26)$ & 22 & 16.8 & \\
\hline Total & 131 & 100 & \\
\hline
\end{tabular}

Table (5): revealed that younger nurses were more knowledgeable ones. A significant relation $(<0.001)$ was found between nurses' age, and their knowledge regarding Zika virus

Table5. Relationship between nurses' age categories and their general knowledge regarding Zika virus.

\begin{tabular}{|c|c|c|c|c|c|c|}
\hline \multirow{2}{*}{ Age category } & \multicolumn{6}{|c|}{ Nurses' general knowledge } \\
\hline & & Poor & Fair & Good & $x 2$ & $\mathrm{P}$ \\
\hline \multirow{2}{*}{$18-20$} & Count & 0 & 12 & 22 & \multirow{8}{*}{122.463} & \multirow{8}{*}{$<0.001^{* * *}$} \\
\hline & $\%$ within age & $0.0 \%$ & $85.7 \%$ & $100 \%$ & & \\
\hline \multirow{2}{*}{$20-22$} & Count & 50 & 2 & 0 & & \\
\hline & $\%$ within age & $52.6 \%$ & $14.3 \%$ & $0.0 \%$ & & \\
\hline \multirow{2}{*}{$22-24$} & Count & 27 & 0 & 0 & & \\
\hline & $\%$ within age & $28.4 \%$ & $0.0 \%$ & $0.0 \%$ & & \\
\hline \multirow{2}{*}{$>24$} & Count & 18 & 0 & 0 & & \\
\hline & $\%$ within age & $18.9 \%$ & $0.0 \%$ & $0.0 \%$ & & \\
\hline
\end{tabular}

*** Highly significant difference. 
Nurses' Awareness Regarding Zika Virusin Beni-Suef Governorate

Table (6): revealed that faculty of nursing graduates had the best score of knowledge. A significant relation $(<0.001)$ was found between nurses' level of education and their knowledge score regarding Zika virus.

Table6. Relationship between nurses' educational level and their Knowledge score regarding Zika virus.

\begin{tabular}{|c|c|c|c|c|c|c|}
\hline \multirow{2}{*}{ Educational level } & \multicolumn{6}{|l|}{ Nurses' knowledge score } \\
\hline & & Poor & Fair & Good & $\chi^{2}$ & $\mathrm{P}$ \\
\hline \multirow{2}{*}{ Diploma } & Count & 41 & 0 & 0 & \multirow{6}{*}{135.524} & \multirow{6}{*}{$<0.001^{* * *}$} \\
\hline & $\%$ within educational level & $43.2 \%$ & $0.0 \%$ & $0.0 \%$ & & \\
\hline \multirow{2}{*}{ institute } & Count & 54 & 14 & 0 & & \\
\hline & $\%$ within educational level & $56.8 \%$ & $100 \%$ & $0.0 \%$ & & \\
\hline \multirow{2}{*}{ Faculty } & Count & 0 & 0 & 22 & & \\
\hline & $\%$ within educational level & $0.0 \%$ & $0.0 \%$ & $100 \%$ & & \\
\hline
\end{tabular}

*** Highly significant difference.

Table(7): shows that nurses' knowledge regarding Zika virus was better among pregnant nurses than nonpregnant ones. A significant relation was found $(<0.001)$.

Table7. Relationship between nurses' pregnancy status and their Knowledge score regarding Zika virus.

\begin{tabular}{|l|l|l|l|l|l|l|}
\hline \multirow{2}{*}{ pregnancy status } & \multicolumn{4}{|l|}{ Nurses' knowledge score } \\
\cline { 2 - 6 } & & Poor & Fair & Good & $\chi 2$ & P \\
\hline \multirow{2}{*}{ pregnant } & Count & 31 & 14 & 22 & & \\
\cline { 2 - 5 } & $\%$ within pregnancy status & $32.6 \%$ & $100 \%$ & $100 \%$ & \multirow{3}{*}{47.419} & \multirow{2}{*}{$<0.001^{* * *}$} \\
\hline \multirow{2}{*}{ Not pregnant } & Count & 64 & 0 & 0 & & \\
\cline { 2 - 5 } & $\%$ within pregnancy status & $67.4 \%$ & $0.0 \%$ & $0.0 \%$ & & \\
\hline
\end{tabular}

*** highly significant difference

\section{DISCUSSION}

Zika virus infection has been considered a public health emergency. As 1.3 million persons have been affected in Brazil alone and 20 countries or territories have reported local transmission of the virus during 2016. Because of the facility of air travel and international trade, more spread into regions where the virus is not endemic is possible, and transmission is likely in sites with mosquito vectors [15].

As nurses comprise the greatest group of health care providers and are the ones responsible for the quality of care provided to the patients, their perspectives on the effectiveness of their care are very important, they should be knowledgeable and possess a wide variety of holistic skills and there is evidence of nursing interventions [16]. Additionally, they should collaborate with other different health professionals to determine the effectiveness of therapy. They should also have the basic necessary knowledge and skills to offer the care safely $[17,18]$. So, the aim of this study was assessing the awareness and knowledge of nurses working antenatal, obstetric and gynecological inpatient ward and outpatient clinics at all government hospitals as well as, all Primary Healthcare Centers regarding Zika virus and its effect on the pregnancy and birth outcome.

Our study revealed that a significant number of nurses did not aware by mode of transmission of Zika virus, this represents one of the challenges against prevention and control of disease in Egypt. A robust, multifaceted response is underway that involves public health authorities, medical practitioners, the biomedical industry, government agencies, and researchers. However, aspects of the virus's vectors, epidemiology, and pathogenesis uncertainty remain debating. Moreover, diagnosis remains unsatisfactory. Diagnostic guidelines are dependent on laboratory testing that is not widely available. Although commercial tests for Zika virus are limited in number 
and availability, more are in development, including prototype multiplex molecular assays that concurrently test for Zika virus, CHIKV, and DENV. However, although not specific to Zika virus, laboratory testing capability is lacking in resource-constrained settings where Zika virus is most prevalent.

Prevention measures (specifically, vector control and environmental sanitation; as reported by our study in table 3) are the main priority; pending advances in diagnostics; the World Health Organization and the Pan American Health Organization have issued recommendations [19]. In the Egypt, multiple factors guard against the explosive epidemic occurring throughout different governorates. Specifically, lower ratios of human crowding in urban areas, wider access to air conditioning and mosquito repellants, and waste management limit mosquito-borne transmission [20]. Furthermore, entomologic research is needed to define the range of Zika virus vectors and identify new locations where autochthonous transmission could take place to enable early intervention. Investment is also needed in durable control measures such as adaptable vaccine platforms for arboviruses; currently, no Zika virus vaccines are in advanced development [21]. Pathogenesis of Zika virus remains unclear. New cases of Zika virus infection should be monitored for complications, particularly in babies born to mothers residing in Zika virus-affected areas. The effects of Zika virus in other vulnerable clinical subsets (e.g., those who have concurrent conditions or are immune-compromised) also evoke further investigation, as does superadded infection or sequential infection by coincident-circulating viruses.

Some researchers denoted possible transfusion-transmitted Zika virus, the pandemic also has implications for the blood supply within Zika virus-endemic and non-endemic regions. The US Food and Drug Administration recommend 28-day deferral for blood donors with confirmed or suspected Zika virus infection [22]. Donor screening by nucleic acid testing is being considered but will be challenging to implement because of high costs and regulatory considerations. Pathogen-reduction technology has shown efficacy for treatment of plasma [23]. The epidemic of Zika virus has serious medical, ethical, and economic problems, especially in countries where the resources for early diagnosis are deficient and potential intervention measures (e.g., contraception or termination of pregnancy) are discouraged or illegal [24]. Continued vigilance is warranted, along with a concerted effort toward improving our understanding, management, and prevention of this emerging pathogen. Our study denoted that large ratio of nurses was not aware of Zika virus as shown in (Table 2). This represents a barrier against preventive measures taken by Egyptian Ministry of Health which shown in (Table 3). The results of the present study regarding the nurses' knowledge of Zika virus revealed that the majority of the nurses hadn't the correct knowledge about mode of transmission, clinical picture, duration of disease, and its effect on pregnancy outcome. This lack of knowledge may be attributed to the lack of or defective curriculum as the $68.0 \%$ of the participant nurses had a technical or secondary level of nursing education.

Congenital microcephaly is a descriptive diagnosis, meaning that the occipital frontal circumference of the head of the newborn child falls below the normal circumference for gestational age, sex and race. The small size of the head is the result of a neurological developmental disorder. When the fetal brain does not increase normally in size, the skull will not grow either and the sutures between the bones that cause premature closure of skull. The diagnosis is often monitored by ultrasonography. According to WHO, microcephaly is defined as a head circumference equal to or lower than two standard deviations below the mean $(\leq-2 \mathrm{SD})$ for age and sex or about less than the second percentile [25]. Head circumference that falls below the -3 SD is sometimes referred to as severe microcephaly. There is an association between the severity of microcephaly and the severity of neurological impairment in Zika virus infection. The disease is reported in the International Statistical Classification of Diseases and Related Health Problems 10th Revision (code Q02) [26].

A close association between Zika virus infection and congenital brain malformation is well established [27]. The epidemiological data available as of November 2015 indicate a ten-fold increase in the incidence of microcephaly among newborns in the north-eastern Brazilian states of Pernambuco, Rio Grande do Norte, and Sergipe. The presence of microcephaly is easy to establish and likely to be detected at birth, during late pregnancy, or very early during childhood. So, a change in detection of microcephaly is unlikely to account alone for the increase. 
Nurses' Awareness Regarding Zika Virusin Beni-Suef Governorate

Our study revealed that significant disorientation by the association of Zika virus and congenital neurological diseases as shown in (table 2\&4).

The first confirmed cases of ZIKV infection in Brazil were reported in May 2015. Transmission of the virus in Brazil is likely to have started several months before because the disease is new and mild, and could have been unrecognized or misdiagnosed, as dengue and chikungunya epidemics were ongoing. Microcephaly when due to an infection is usually caused by trans-placental infections occurring early in pregnancy and tends to be detected only during the second half of pregnancy or after birth. The observed six months' delay between the recognition of the transmission of ZIKV in May 2015, and the detection of an increase in microcephaly in November 2015, is, therefore, compatible with a temporal association between the two events.

Initial investigations suggest an increase of microcephaly in some states where ZIKV circulation has been detected, suggesting a spatial association between the two events.

The materno-foetal transmission has been demonstrated for several Flavi viruses (dengue, West Nile fever) and other Flavi virus infections are known to have the ability to cause premature birth, congenital defects, and microcephaly. For example, the risk of vertical transmission with dengue virus exists, but whether maternal dengue infection is a significant risk for adverse pregnancy outcome remains inconclusive [28]. Among our nurses and pregnant women as shown in table 6, a significant number of them are oriented by disease after pregnancy not before, these acts as a barrier against prevention of the disease. Serum and cerebrospinal fluid (CSF) of the two infants were negative for WNV IgM antibodies. Likewise, cord blood, cord tissue, and the placenta were negative for WNV RNA by RT-PCR. WNV infection in the mother probably occurred during the second semester [29]. These laboratory findings were not available in our study as shown in tables 3,4 \& 6

RNA of ZIKV was reported in amniotic fluid samples collected from two pregnant women with foetal microcephaly from the state of Paraíba in 2015 [30]. This demonstrates trans-placental capabilities of ZIKV and the possibility of the infection of the foetus.

Moreover, increases of central nervous system congenital defects in fetuses and newborns have been reported in French Polynesia following an epidemic of ZIKV infection [31]. Other causes of microcephaly and possible predisposing factors should be systematically investigated such as previous or concomitant infections, individual genetic risk factors, or other etiologies such as environmental exposures to chemicals or consumption of teratogenic drugs. In addition, other infections, including those caused by the STORCH group of diseases, have been associated with such congenital defects as well and cannot, therefore, be ruled out. In conclusion, a causative association between microcephaly in newborns and ZIKV infection during pregnancy is plausible, but not enough evidence is available yet to confirm or refute it.

The increase in congenital microcephaly observed in Zika virus is of concern. Its emergence a few months after the infection of ZIKV infection raises questions about the possible role of the infection in congenital microcephaly. Further investigations and studies will contribute to a better characterization of the association, and provide a better understanding of the possible role of other prenatal infections, genetic risk factors, environmental exposures to chemicals or consumption of teratogenicity drugs. Studies of the ZIKV genetics will provide knowledge on possible changes that might affect ZIKV disease characteristics and vector competence.

The results of the present study regarding the nurses' knowledge of Zika virus revealed poor nurses' knowledge about complication; precautions are taken and prophylactic measures. It was observed that $72.5 \%$ if nurses had poor knowledge score and $10.7 \%$ had a fair score, while only $16.8 \%$ had a good score. In brief, the total score of nurses' knowledge regarding Zika virus was $20.14 \pm 5.94$

In the present study, nurses' age was an important factor for her knowledge score. Younger nurses scored better grades. They were more knowledgeable than older ones. A significant relation was found between nurses' age, and their knowledge regarding Zika virus. This is may be attributed to younger nurses are still newly graduates 
and have the ability to read and search. The findings were not in line with the fact that day-by-day life enhances the nurse's experiences and improve their knowledge [13].

According to the results of the current study, more than two-thirds of the study sample had secondary or technical institute level of nursing education. This is in agreement with the findings of Farag M. (2012) who found 3 types of nursing education relating to three types of nurses in Egypt today. The first level is carried out within high schools for nursing education akin to a sort of vocational education that takes place in lieu of high school (referred to as secondary level school in Egypt). The second level is carried out within a technical institute of nursing education (two years of after high school nursing education). The third or highest level is attained via a University college of nursing (students are trained over four years plus a one-year internship within a post-secondary school education or technical institute of nursing) [32]. The health sector in Egypt suffers from a severe shortage of qualified nurses (nurses with the at least technical institute, or 2 years of post-high school nursing education). The shortage has implications both for the quality of healthcare as well as the efficiency of the production of health services. The majority of nurses in Egypt (approximately 90\%) are high school level nurses reflecting an inadequate/insufficient quality of nursing education not only by internationally but even by the region's local standard. The current approach by the Ministry of Health and Population is to upgrade the standard of quality of nursing education in Egypt to eliminate high school level nursing education in the future; this seems to be the right approach [33].

The results of our study revealed that faculty of nursing graduates had the best score of knowledge regarding Zika virus. There is a statistical difference between nurses' knowledge and their level of education, it was observed that generally nurses who have higher educational having higher knowledge score than lower ones. This is due to that; the higher educated nurse may have better chances for scientific information. These findings are supported by Sabilu Y. et al., (2016) who reported, the level of education affects the learning process and the higher the person's level of education the easier person to receive information. However, it should be emphasized that a low education does not mean absolute knowledge also lower. Increased knowledge is not absolute acquired in formal education. There are several factors that influence a person's knowledge, among others, intelligence, experience, information, health education given through the media information [34].

According to the results of the current study, about half of the study sample was pregnant. Moreover, the results showed that nurses' knowledge regarding Zika virus was better among pregnant nurses than non-pregnant ones. A significant relation was found $(<0.001)$. All nurses who gained good and fair score were pregnant while poor score reported by only $32.6 \%$ of pregnant nurses. This is may be attributed to that pregnant one will be more considerate about for getting better pregnancy outcome.

As a precautionary measure taken by the Ministry of Health of Egypt emphasizes the significance of recommendations that pregnant women should avoid the consumption of drugs or medications without prescription by physician and contact with people presenting with fever or infection. Also, specific recommendations were issued about protection from mosquito bites, such as keeping doors and windows closed or screened, wearing trousers and long-sleeved shirts and using repellents authorized during pregnancy. In the view of the current speculation regarding a yet to be established link between ZIKV and neurological malformations, options for public health authorities in ARE Member States to consider for mitigation of risks for travellers to and from Egypt include: 1) Increase awareness of clinicians, nurses, pregnant women and travel health clinics about the evolution of the ZIKV outbreak and the endemic areas, especially in Brazil, Colombia, Suriname, Samoa and Cape Verde, in order for them to include ZIKV infection in their differential diagnosis for travelers from those areas. Fever and/or macular or papular rash not attributable to dengue or chikungunya infection among travelers returning from areas currently experiencing ZIKV outbreak should be considered indications for further investigation for ZIKV infection. Our study revealed that most of the nurses were not oriented by clinical presentation of Zika virus which represents another challenge to overcome this disease; 2) 
Ensure that advice on specific prevention procedures, including knowledge and education about mosquito bite prevention, is directed to pregnant women living in or travelling to areas where ZIKV outbreaks are ongoing; 3 ) Increase awareness among health professionals providing prenatal care of this possible association and good prenatal monitoring according to the exposure of the pregnant women, 4) advise travellers visiting affected areas, particularly pregnant women, to take individual protective measures to prevent mosquito bites all day round as ZIKV is transmitted by a daytime mosquito and consequently protective measures must be applied during the day (unlike malaria), 5) strengthen the laboratory facilities to confirm suspected ZIKV infections, 6) Consider deferral of donors for blood safety authorities in areas with active ZIKV transmission.

\section{CoNCLUSION}

Most of the nurses working at antenatal, obstetric and gynecological inpatient ward and outpatient clinics at all government hospitals as well as, all Primary Healthcare Centers in Beni-Suef City were not oriented by Zika virus and had poor knowledge score. They didn't know the main mode of disease transmission, didn't know that Zika virus may affect their pregnancy outcome. Younger age, better education, and pregnant nurses were more knowledgeable comparing with older, lower educational level and non-pregnant ones.

\section{RECOMMENDATIONS}

1. Implement health education program to increase awareness of the nurses working in outpatient clinic about Zika Virus and its effects on pregnant women and birth outcome.

2. Moreover, specific recommendations were done about protection from mosquito bites, such as keeping doors and windows closed or screened, wearing trousers and long-sleeved shirts and using repellents authorized during pregnancy. This issue is most important because our study confirmed that most of the nurses and pregnant women especially of a low educational level were not oriented by precautions taken against infection by Zika virus.

3. Increase awareness among health professionals providing prenatal care and continued the epidemiologic study, combined with research involving animal models, will offer high light on the Zka virus.

\section{REFERENCES}

1. Chastain, Mary. National Institutes of Health: Zika Virus Is a 'Pandemic'”. Breitbart. 2016

2. Sikka, Veronica; Chattu, Vijay Kumar; Popli, Raaj K.; et al. The emergence of zika virus as a global health security threat: A review and a consensus statement of the Indusem Joint working Group (JWG)". Journal of Global Infectious Diseases, 2016; 8 (1): 3-15. doi:10.4103/0974-777X.176140.

3. Pierson, TC, Diamond, MS. Degrees of maturity: the complex structure and biology of flavi viruses. Current opinion in virology, 2012; 2 (2): 168-75. doi:10.1016/j.coviro.2012.02.011. PMC 3715965. PMID 22445964.

4. Symptoms, Diagnosis, \& Treatment. Zikavirus. Atlanta: Centers for Disease Control and Prevention. 2016

5. CDC Zika: Transmission. U.S.Centers for Disease Control and Prevention. 2016.

6. Rasmussen, Sonja A., Jamieson, Denise J., Honein, Margaret A., Petersen, Lyle R.Zika Virus and Birth DefectsReviewing the Evidence for Causality. New England Journal of Medicine 374:1981-1987. doi:10.1056/ NEJMsr1604338. Retrieved 15 April 2016.

7. Musso, Didier, Roche, Claudine, Robin, Emilie, Nhan, Tuxuan; Teissier, Anita, Cao-Lormeau, Van-Mai (February 2015). Potential Sexual Transmission of Zika Virus. Emerging Infectious Diseases 21 (2): 359361. doi:10.3201/eid2102.141363. PMC 4313657.PMID 25625872. 
Nurses' Awareness Regarding Zika Virusin Beni-Suef Governorate

8. Nhan, T, Musso, D, Robin, E, et al. Potential for Zika virus transmission through blood transfusion demonstrated during an outbreak in French Polynesia, November 2013 to February 2014. Eurosur veillance 19 (14). PMID 24739982.

9. WHO Director-General summarizes the outcome of the Emergency Committee regarding clusters of microcephaly and Guillain-Barré syndrome. World Health Organization. February 2016.

10. Petersen, Emily E., Staples, J. Erin; Meaney-Delman, Dana, et al. Interim Guidelines for Pregnant Women During a Zika Virus Outbreak-United States, 2016. MMWR. Morbidity and Mortality Weekly Report 65 (2): 30-33. doi:10.15585/mmwr.mm6502e1.PMID 26796813.

11. Malone, Robert W., Homan, Jane, Callahan, Michael V., et al. Zika Virus: Medical Countermeasure Development Challenges". PLOS Neglected Tropical Diseases, 2016; 10 (3): e0004530. doi:10.1371/journal. pntd.0004530.

12. MegahedKh. Egypt prepared for prevention of Zika outbreak, 2016. http://www.amoraview.com/egyptprepared-for-prevention-of-zika-outbreak/

13. Hassan H, Nasr E. Improving nurses' knowledge and skills regarding tocolytics for inhibiting preterm labor. Clinical Nursing Studies. 2017; 5(1): 1-12. https://doi.org/10.5430/cns.v5n1p1.

14. Emily E., Petersen, Polen, Kara N.D., Meaney-Delman, Dana, et al. Update: Interim Guidance for Health Care Providers Caring for Women of Reproductive Age with Possible Zika Virus Exposure-United States, 2016. MMWR. Morbidity and Mortality Weekly Report 65 (12). doi:10.15585/mmwr.mm6512e2er.

15. Zika: Olympics plans announced by Rio authorities. BBC. 24 January 2016. Retrieved 24 January 2016. The Rio de Janeiro authorities have announced plans to prevent the spread of the Zika virus during the Olympic Games later this year. The US, Canada and EU health agencies have issued warnings saying pregnant women should avoid traveling to Brazil and other countries in the Americas which have registered cases of Zika.

16. Hassan H., Mohamady Sh., \& Abd El-Gawad N. Protocol for improving nursing performance towards placental examination at labor units. Clinical Nursing Studies, 2017; 5(2): 1-11. http://dx.doi.org/10.5430/ cns.v5n2p1.

17. Gomez R, Romero R, Medina L. Cervicovaginal fibronectin im- proves the prediction of preterm delivery based on sonographic cervical length in patients with preterm uterine contractions and intact membranes. Am J Obstet Gynecol. 2005; 192: 350-359. [Er- ratum, Am J Obstet Gynecol. 2005; 193: 308-9.] PMid: 15695971. https://doi.org/10.1016/j.ajog.2004.09.034

18. Nasr E, Hassan H. Association between quality of family planning services and client's satisfaction level in maternal and child health centers in Port Said city. Journal of Nursing Education and Practice. 2016; 6(1): 85-99.

19. Instituto Nacional de Salud. Boletín Epidemiológico Semanal. Semena; Brazil. Emerging Infectious Disease journal. 2015; 21(10):1885.

20. Zika virus infection outbreak, Brazil and the Pacific region. Rapid Risk Assessments. Stockholm: European Centre for Disease Prevention and Control. 25 May 2015. pp. 4-5. Retrieved 12 February 2016.

21. Fauci AS., Morens DM. Zika virus in the Americas-yet another arbovirus threat. N Engl J Med. 2016; 374: 601-4. 
Nurses' Awareness Regarding Zika Virusin Beni-Suef Governorate

22. US Food and Drug Administration. Recommendations for donor screening, deferral, and product management to reduce the risk of transfusion transmission of Zika virus, recommendations for industry. 2016.

23. Gatherer, Derek; Kohl, Alain. Zika virus: a previously slow pandemic spreads rapidly through the Americas. Journal of General Virology, 2015; 97 (2): 269-273. doi:10.1099/jgv.0.000381. PMID 26684466.).

24. Musso, D.; Nilles, E.J.; Cao-Lormeau, V.-M. Rapid spread of emerging Zika virus in the Pacific area. Clinical Microbiology and Infection, 2014; 20 (10): 0595-6. doi:10.1111/1469-0691.12707. PMID 24909208.

25. Pan American Health Organization (PAHO)/World Health Organization (WHO). Epidemiological Alert: Increase of microcephaly in the northeast of Brazil - 17 November 2015.

26. International Statistical Classification of Diseases and Related Health Problems. Microcephaly Q02. 2015.

27. Microcephaly in Brazil potentially linked to the Zika virus epidemic, ECDC assesses the risk". News and Media. European Centre for Disease Prevention and Control. 25 November 2015. Retrieved 18 January 2016.

28. Pouliot SH, Xiong X, Harville E, Paz-Soldan V, Tomashek KM, Breart G, et al. Maternal dengue and pregnancy outcomes: a systematic review. Obstet Gynecol Surv. 2010; 65(2):107-18.

29. O’Leary DR, Kuhn S, Kniss KL, Hinckley AF, Rasmussen SA, Pape WJ, et al. Birth outcomes following West Nile Virus infection of pregnant women in the United States: 2003-2004. Pediatrics. 2006;117(3):e537- 45.

30. Ministério da Saúde (Brazil). Microcefalia-Ministério da Saúdedivulgaboletimepidemiológico. Brasília: Ministério da Saúde; 2015.

31. Government of the Federated States of Micronesia. Population Census 2000, 2015

32. Farag M. School of Public Health University of Saskatchewan. 2012.

33. Farag M. Belfer Center for Science and International Affairs, Harvard University. 2008.

34. Sabilu Y, Kusnan A, Saptaputra S, et al. The Sexually Transmitted Infection (STI) In Women Sexual Workers (WSW) in Southeast Su- lawesi Province. IOSR Journal of Nursing and Health Science. 2016; 5(6):119-122. https://doi:10.9790/1959-050601119122.

Citation: Ahmed Abd-Elhakim Elgendy, Hanan Elzeblawy Hassan, Fathya Elsaid Elsaid, Eman EL_Sherbeny, "Nurses' Awareness Regarding Zika Virusin Beni-Suef Governorate". American Research Journal of Public Health; 1(1): 30-42.

Copyright (c) Ahmed Abd-Elhakim Elgendy, Hanan Elzeblawy Hassan, Fathya Elsaid Elsaid, Eman EL_Sherbeny, This is an open access article distributed under the Creative Commons Attribution License, which permits unrestricted use, distribution, and reproduction in any medium, provided the original work is properly cited. 